\title{
La necrópolis septentrional de Icosium (Argel). Revisión e interpretación de su cultura material (siglos I-V d. C.)
}

\section{The northern necropolis of Icosium (Algiers). A revision and interpretation of the material culture (1st-5th centuries AD)}

\author{
Alejandro Quevedo \\ Universidad de Murcia. Área de Arqueología \\ C/ Santo Cristo, 1, E-30001 Murcia \\ alexquevedo@um.es \\ NACÉRA BENSEDdIK \\ École Supérieure des Beaux-Arts d'Alger \\ Parc Ziryab, 140 Bd Krim Belkacem, Alger \\ benseddikn@gmail.com
}

Icosium es una de las ciudades romanas menos conocidas del norte de África. Debido a la escasez de referencias literarias y epigráficas, la arqueología es la principal fuente para profundizar en su pasado histórico. El presente trabajo está dedicado al estudio de los ajuares de la necrópolis de Bab-el-Oued, descubierta a finales del siglo XIX y desaparecida hoy día. El análisis pretende matizar la cronología del conjunto, proporcionar una nueva visión sobre las prácticas funerarias de la época y plantear nuevas cuestiones sobre el desarrollo de este espacio periurbano de Argel durante la Antigüedad.

PALABRAS CLAVE

MAURETANIA CAESARIENSIS, ARGELIA, CERÁMICA, VIDRIO, CREMACIÓN, INHUMACIÓN

Icosium (Roman colony and precursor of Algiers) is one of the less known Roman cities in North Africa. Archaeology is the principal source for a more detailed evaluation of its historical past due to the scarcity of literary and epigraphic references. This paper analyses the grave goods of the necropolis of Bab-el-Oued, discovered at the end of the 19th century but now lost. The main purpose is to refine the chronology of the assemblage, to provide a new vision of funeral practices of the period and to raise new questions about the development of this suburban site of Algiers during Antiquity.

\section{KEYWORDS}

MAURETANIA CAESARIENSIS, ALGIERS, POTTERY, GLASS, CREMATION, INHUMATION 


\section{Introducción}

Bajo la capital de la actual Argelia se encuentra la ciudad romana de Icosium, a los pies de un acantilado litoral de $100 \mathrm{~m}$ de altura que desciende de forma abrupta sobre el Mediterráneo (fig. 1). 'Yksm, también llamada «Isla de las gaviotas», «Isla de los búhos» o «Isla de las lunas llenas», fue probablemente fundada en el siglo III a. C., frente a cuatro islotes, un excelente fondeadero para embarcaciones y una posición fácil de defender: el yacimiento fenicio por excelencia. El paso de Hércules por este lugar y la fundación de la ciudad por sus veinte compañeros (eikosi, veinte en griego) se basa en una leyenda transmitida por el gramático del siglo III d. C. Solino (XXVI, 17). Gracias a los escritos de A. Berbrugger, A. Devoulx y P. Gavault, quienes preservaron en el Musée National des Antiquités (en adelante, MNA) los valiosos restos de la ciudad antigua, y a sus propias investigaciones, S. Gsell legó una primera síntesis arqueológica sobre Argel en 1911. Casi cincuenta años después, M. Le Glay (1968) partía de nuevo "a la búsqueda de Icosium», parafraseando su célebre artículo, y completaba el trabajo de Gsell. Entrado el siglo xxI, en un momento en el que los barrios históricos de Argel son presa de devastadoras fiebres constructivas y destructivas, las fuentes

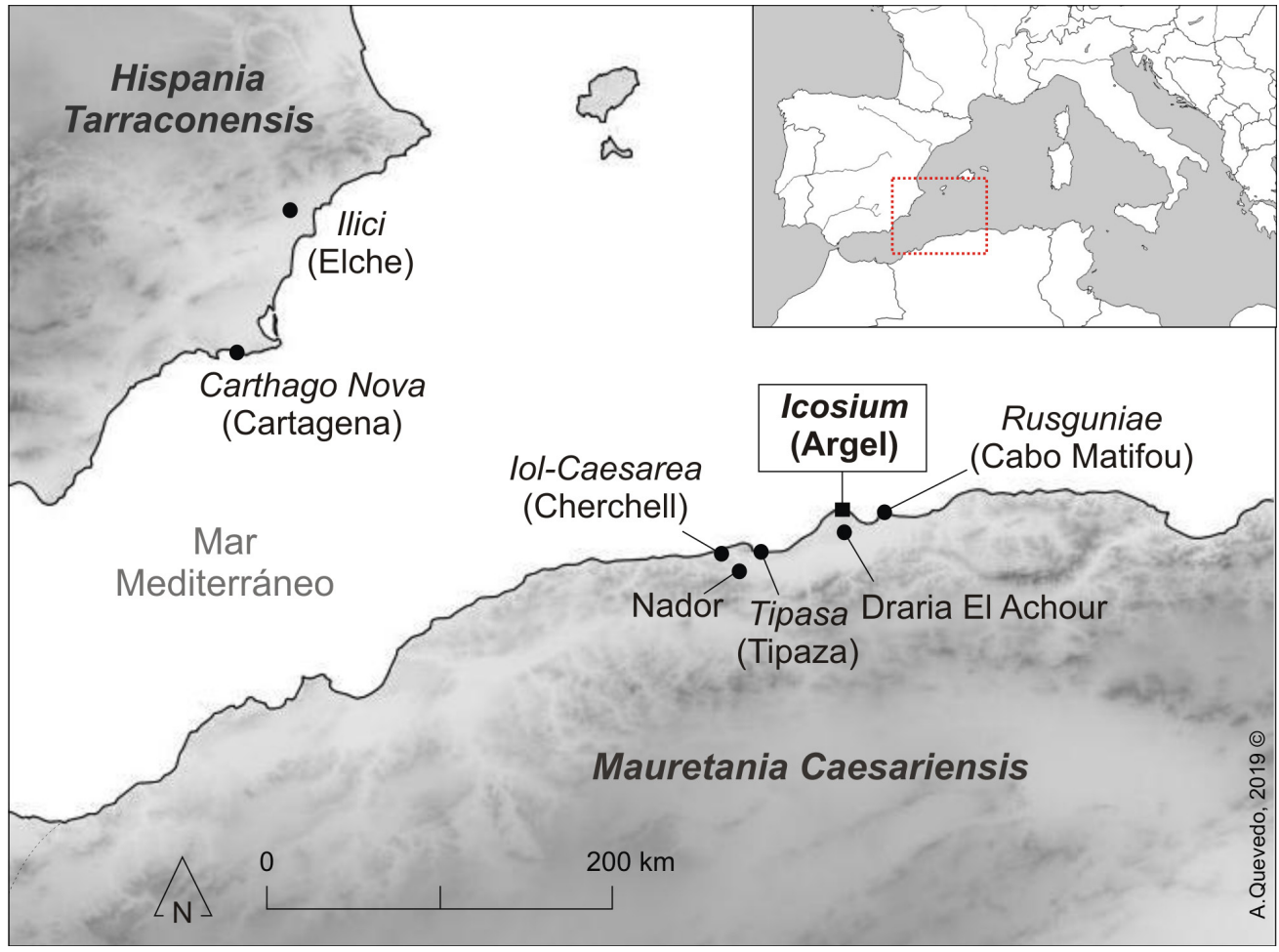

Figura 1. Mapa del Mediterráneo occidental con los principales topónimos citados en el texto (A. Quevedo, sobre base de B. Vallori). 
para una historia de la Ikosim númido-púnica y la Icosium romana continúan siendo de origen casi exclusivamente arqueológico (Benseddik, 2004).

El perímetro de la ciudad romana y dos de sus accesos principales quedaron fosilizados por la muralla de la medina moderna y por dos de sus puertas: Bab-Azzoun en el sector meridional y Bab-el-Oued en su parte septentrional (Messikh, 2015). Al exterior de las mismas se encontraban los cementerios de época otomana, bajo los cuales se descubrieron en el siglo XIX las necrópolis antiguas, que tomaron el nombre de dichas puertas. A partir de 1830, tras la toma de Argel por los franceses, comenzó una rápida urbanización que vio desaparecer estos espacios periurbanos y muchos otros monumentos (Benseddik, 2000: 768-771). De la necrópolis de Bab-Azzoun solamente se conservan algunas inscripciones fuera de contexto. Sin embargo, en el caso de la necrópolis de Bab-el-Oued se documentaron varias tumbas y, aunque todas se perdieron, una parte de los ajuares fueron preservados. Estos materiales, los únicos que han llegado a nuestros días de este espacio funerario, se encuentran depositados en el MNA y están formados mayoritariamente por cerámica y vidrio.

A partir de 2014, en el marco de un proyecto sobre la arqueología de Icosium coordinado por N. Benseddik (e. p.), surge la posibilidad de revisar los ajuares de la necrópolis de Bab-el-Oued. Se trata de una colaboración argelino-española inédita que ha permitido trabajar en los fondos del MNA por primera vez desde que terminara la guerra de independencia en 1962. Las piezas poseen un gran valor documental para la Argel romana, ya que otros contextos destacados como el del pozo del barrio de La Marine (Le Glay, 1968: 14-16) se hallan desaparecidos y los de la excavación de Sahet echouada, la Plaza de los Mártires, están en curso de estudio ${ }^{1}$. Es, por tanto, el lote de material más completo conservado actualmente en una ciudad que, a diferencia de sus vecinas Cherchell (Iol) Caesarea) y Tipaza (Tipasa), adolece de restos arqueológicos de entidad.

\section{La necrópolis de Bab-el-Oued: breve historia de su descubrimiento}

En la actualidad Bab-el-Oued, "la puerta del arroyo», es un barrio popular de Argel densamente poblado que toma su nombre del acceso situado junto al riachuelo Atoun o M'Kacel. Se trata en realidad de una rambla que marcaba el límite norte de la ciudad hasta el siglo XIx. De aquí partía en época antigua la vía que conducía a Tipasa (Desanges et al.,

1 Operación arqueológica realizada entre 2013 y 2017 a los pies de la Casbah de Argel, gracias a una colaboración entre el Centre National de Recherche en Archéologie (CNRA, Argelia) y el Institut National de Recherches Archéologiques Préventives (INRAP, Francia). Esta excavación de $8.000 \mathrm{~m}^{2}$, motivada por la ampliación de la línea de metro y por el grado de protección del que goza la zona, patrimonio mundial de la UNESCO, ha hecho emerger diferentes fases de ocupación que se extienden desde época antigua hasta el siglo 11. A. Quevedo se ocupa del estudio de los contextos de época romana. Una publicación conjunta argelino-francesa está prevista para 2021. 


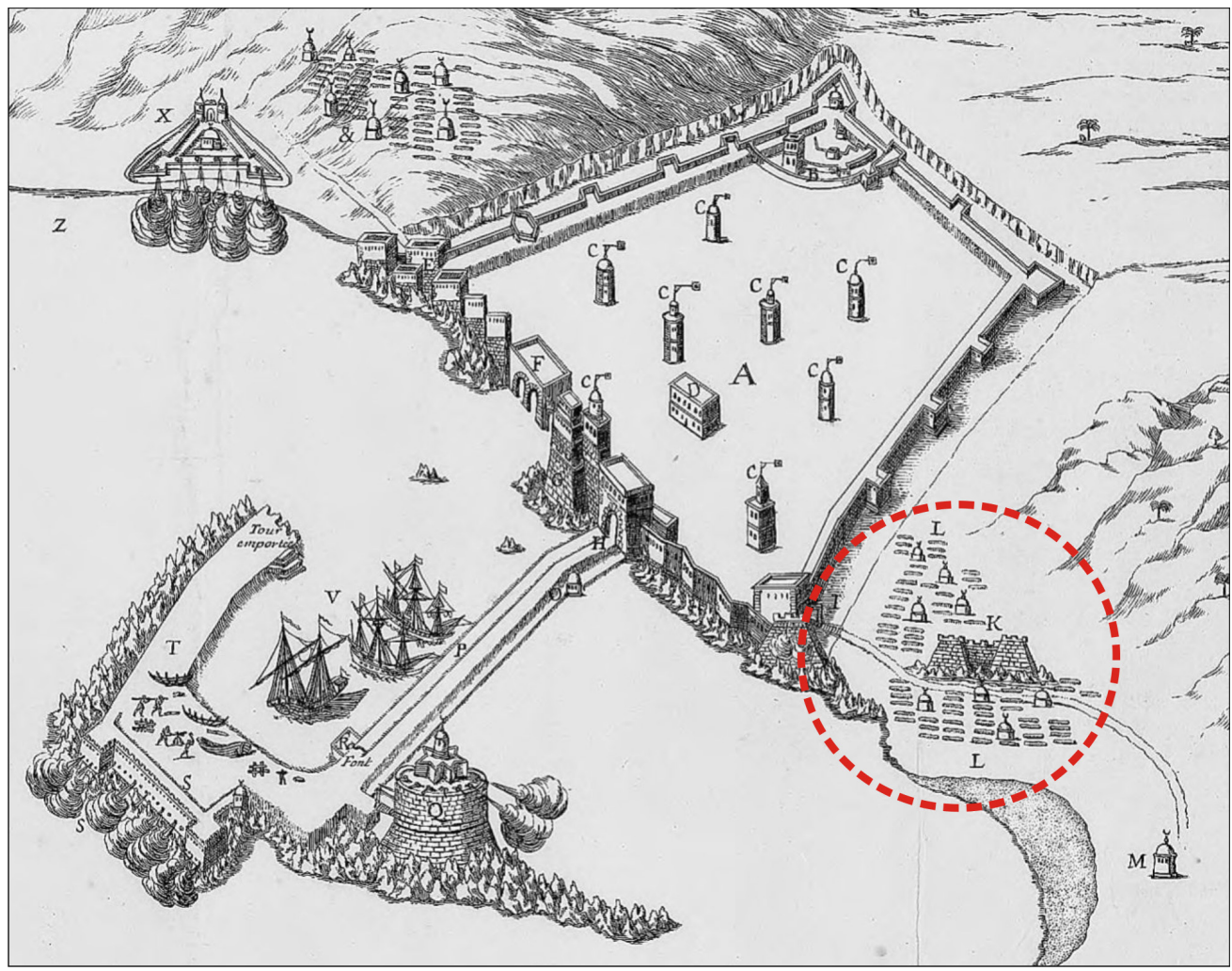

Figura 2. Argel, 1665. Las necrópolis otomanas se sitúan fuera de las puertas principales de la ciudad: en rojo, Bab-el-Oued (Bibliothèque Nationale de France).

2010), flanqueada a ambos lados por la necrópolis extra moenia objeto de nuestro estudio. En el interior de las murallas, la calzada se transformaba en un cardo ancho de entre 5,60 y 5,85 metros, con probabilidad el cardo máximo. El mantenimiento de su trazado en época otomana y su ampliación a partir de la llegada de los franceses en 1830 (Dumassy, 2016: 99) refleja la importancia histórica de este eje de circulación dentro de la trama urbana.

La necrópolis de Bab-el-Oued se sitúa a 20 m sobre el nivel del mar y a proximidad del mismo, en un punto del litoral formado por pequeñas calas rocosas y una playa que se extiende a los pies de la colina de Bouzaréah. La zona estuvo ocupada desde época otomana por el cementerio de los Deys (fig. 2) y distintos edificios defensivos (Haedo, 19271929 [1612]: 185-186 y 198-199; Devoulx, 1863: 102-113). No será hasta el período que discurre entre el segundo cuarto del siglo XIX y las primeras décadas del siglo Xx cuando la topografía de este sector, denominado «faubourg de Bab-el-Oued», se verá profundamente alterada (fig. 3). En 1833 se construye el Jardin des Condamnés, futuro Jardin Marengo 
Figura 3. Área de extensión de la necrópolis de Bab-el-Oued

y principales solares donde se hallaron restos arqueológicos de la misma (A. Quevedo, sobre base de Google Maps (C) 2019).

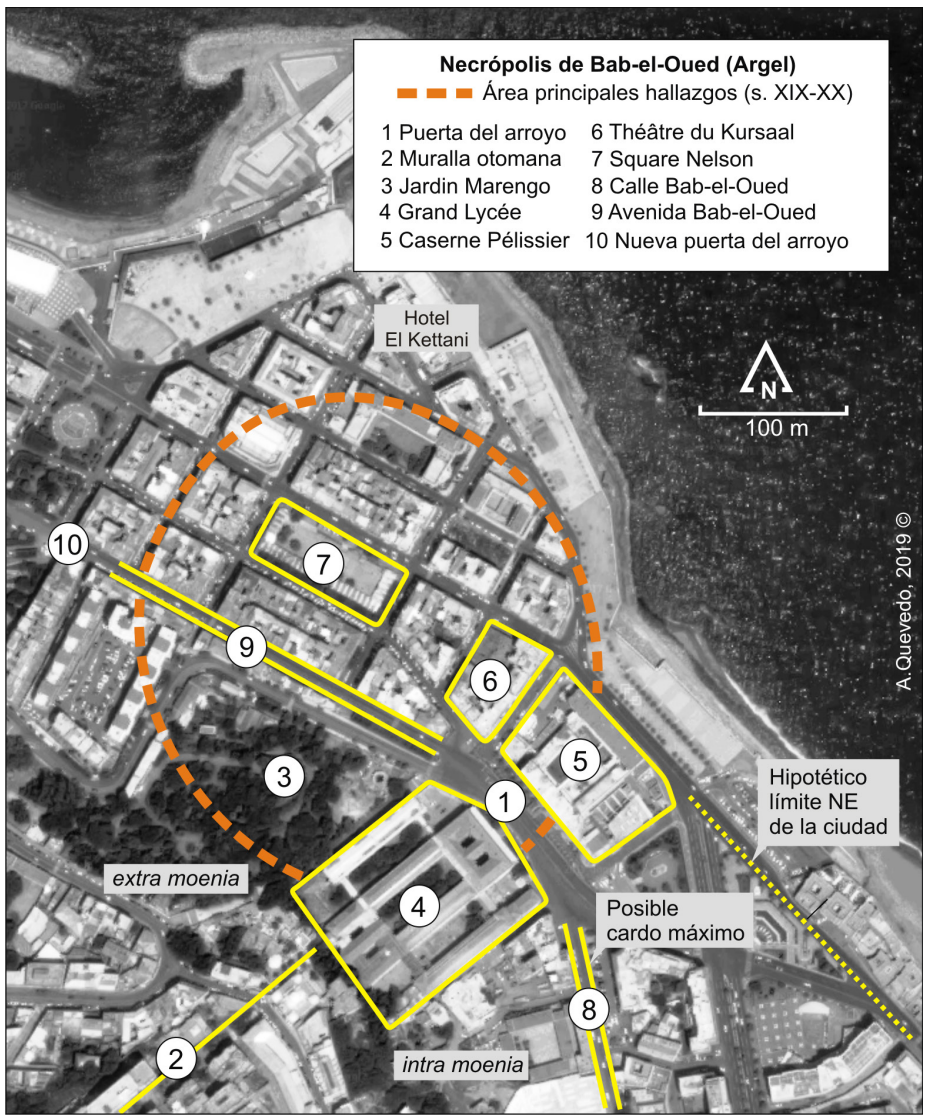

y hoy Jardin de Prague. Asimismo, el crecimiento de la ciudad provoca el desplazamiento de la puerta de Bab-el-Oued $350 \mathrm{~m}$ hacia el noroeste, destruyendo el acceso otomano y los fortines situados alrededor. Entre 1862 y 1868 se levanta en este espacio un edificio de volumen imponente, el Grand Lycée de Argel (después Lycée Bugeaud y actualmente Lycée Emir Abd-el-Kader). La excavación de sus potentes cimentaciones sacó a la luz una parte del cementerio otomano. Bajo el mismo, a una profundidad de entre 8 y 12 metros, se encuentran algunas tumbas antiguas (Berbrugger, 1862:311-315). Frente al liceo se alza la Caserne Pélissier, cuyo emplazamiento ocupa actualmente la Direction Générale de la Sécurité Nationale (DGSN), y, al norte de la misma, en 1903, el casino-teatro del Kursaal, conocido posteriormente como el Nouveau Théâtre. Durante la construcción de este último edificio, desaparecido en 1928, se descubrieron varias tumbas. Un poco más al norte, una gran esplanada que funcionaba como plaza de armas fue urbanizada hasta convertirse en un nuevo barrio, el Quartier Nelson. Los trabajos realizados durante su 
construcción, entre 1903 y 1912, sacaron a la luz una parte importante de la necrópolis, formada por diversos enterramientos (Le Glay, 1968: 28-32). También se descubrieron entonces la inscripción de un soldado de la legio IV Flavia Felix (Gsell, 1909: CLXXX), de mediados del siglo II d. C., y algunos epitafios anepígrafos (acaso pintados originalmente), como una estela con la representación de un caballero. Otras inscripciones halladas entre la puerta de Bab-el-Oued y el barrio de La Marine no pueden atribuirse con certitud a esta necrópolis, dado que pudieron ser desplazadas de su ubicación original. De hecho, desde época otomana, epígrafes y elementos arquitectónicos procedentes de yacimientos próximos como Matifou o Tipaza son llevados hasta Argel para ser reutilizados (Gsell, 1911:2, hoja n. ${ }^{\circ}$ 5, voz: Alger), lo que otorga una mayor importancia - si cabe- a la necrópolis y sus ajuares, que pueden vincularse sin lugar a dudas a la ciudad.

\section{Metodología y objetivos}

A partir de antiguas descripciones de los hallazgos conservadas en el MNA y de una revisión exhaustiva de la documentación publicada, se plantea una reconstitución del contexto original de los ajuares funerarios y su reinterpretación. La referencia principal para llevar a cabo este proceso es el trabajo de Adrien Berbrugger (1801-1869), que gracias a su condición de inspector general de los monumentos históricos y los museos arqueológicos de Argelia pudo supervisar algunas intervenciones personalmente, en especial la del Grand Lycée. Las publicaciones de este meticuloso investigador, que llegó a aplicar algunos principios de la estratigrafía moderna, son la mejor fuente para conocer la necrópolis de Bab-el-Oued. Tras su muerte, una recopilación de sus notas sobre las tumbas antiguas de Argel fue publicada en la Revue Africaine (Berbrugger, 1875: 389-414), una documentación mucho más exhaustiva que la generada durante los trabajos arqueológicos en la zona en las primeras décadas del siglo xx.

No obstante, aunque Berbrugger fue quien registró los hallazgos a pie de campo, otros autores se interesaron por la cuestión. En su síntesis sobre las evidencias arqueológicas de Icosium, Marcel Le Glay también dedicó algunas páginas al estudio de los materiales procedentes de Bab-el-Oued (Le Glay, 1968: 31-39, fig. 19-20). En ellas, sin embargo, trataba como un lote homogéneo objetos en apariencia muy distantes cronológicamente y pertenecientes según él a la misma cámara funeraria, que fechaba entre los siglos II-III d. C. Para comprender esta interpretación es importante recordar que el origen de su trabajo se remonta a una conferencia-visita que este especialista en epigrafía organizó en el museo en 1959 (Le Glay, 1968: 7), donde las piezas se exponían como si hubiesen aparecido en una misma tumba. Además de esta contribución cabe señalar otros trabajos dedicados a estos ajuares, como el llevado a cabo por D’Escurac-Doisy (1966-1967) sobre el vidrio y dos catálogos recientes del MNA en los que se publican algunas de las piezas de forma descriptiva (Akkab y Cheniti, 2007: 102-135; AA. VV., 2014: 26-40). 
Nuestro examen está consagrado principalmente al vidrio y la cerámica, dado que los objetos metálicos se encuentran peor conservados y son más difíciles de asociar a tumbas particulares.

Sorprende la ausencia de producciones en cerámica común, un fenómeno que cabe vincular al modo en que se formaron las colecciones del MNA entre finales del siglo XIX y la primera mitad del xx, donde se privilegiaba la recogida de los objetos considerados más estéticos, generalmente cerámicas finas y vidrio. Aun siendo conscientes de la necesidad de aplicar análisis arqueométricos, el excepcional estado de conservación de las piezas y la legislación vigente en el país ha impedido la realización de los mismos, lo cual no invalida su valor como fuente documental. Mediante esta nueva aproximación a los ajuares de Bab-el-Oued se persigue un triple objetivo: obtener nuevos datos sobre las prácticas funerarias en Icosium, matizar la composición del conjunto y su cronotipología y comprender la evolución del sector periurbano septentrional de la colonia en la Antigüedad.

\section{La necrópolis de Bab-el-Oued: cultura material}

Sobre la base de los distintos hallazgos, estimamos que la necrópolis tuvo una superficie en torno a los $50.000 \mathrm{~m}^{2}$, si bien se desconoce cuál fue su densidad de ocupación. Aunque su pleno desarrollo no parece anterior al siglo i d. C., algunas cerámicas comunes procedentes de las intervenciones realizadas en la zona podrían sugerir la existencia de una fase púnica. Se trata de piezas definidas como cerámica de pasta blanca (céramique à pâte blanche, CPB), una producción de color blanquecino-amarillento con desgrasantes arenosos de entre 1-3 mm, micaesquistos e inclusiones de cal ligeramente más grandes, que confieren un acabado rugoso a su superficie, que nunca presenta engobe (Quevedo, 2019: 67). Se desconoce cuándo empiezan a producirse, aunque algunas como una jarra de cuerpo semiesférico estrangulado en su base (fig. 4.1) remite a paralelos de Cartago de los siglos IV-III a. C. (Lancel, 1987: 113, Pl. 18, tipo 521bl). La forma es muy similar al tipo 6 de Gsell, más estrecho y con el cuerpo ligeramente acanalado, bien documentado en Tipasa en tumbas fechadas entre los siglos I a. C. y I d. C. (Baradez, 1957: vid., entre otros, los perfiles completos de las Pl. II, 10b, Pl. III, 15a, Pl. IV, 25a y 26). Las jarras y jarritas monoansadas, en diversas variantes, son las formas más abundantes (fig. 4.2). Una de sus características principales es la unión del asa, que se produce siempre en el interior del borde, siguiendo una tradición que remite de nuevo a horizontes púnicos (Cintas, 1950: 100-113, Pl. VIII-XI; para las formas con el remate superior del asa en el interior del borde, vid. los tipos 104-148). En la necrópolis de Tipasa se documentan ejemplares con estas características fechados entre los siglos III-II a. C. (Cintas, 1948: 298-300, fig. 11).

En cualquier caso, el grueso del material estudiado, desarrollado en las páginas que siguen, es de época romana. Los ajuares se presentan siguiendo un orden diacrónico y, a su vez, se agrupan en función del tipo de sepultura, distinguiendo entre cámaras sepulcrales, donde predominan las cremaciones, e inhumaciones 

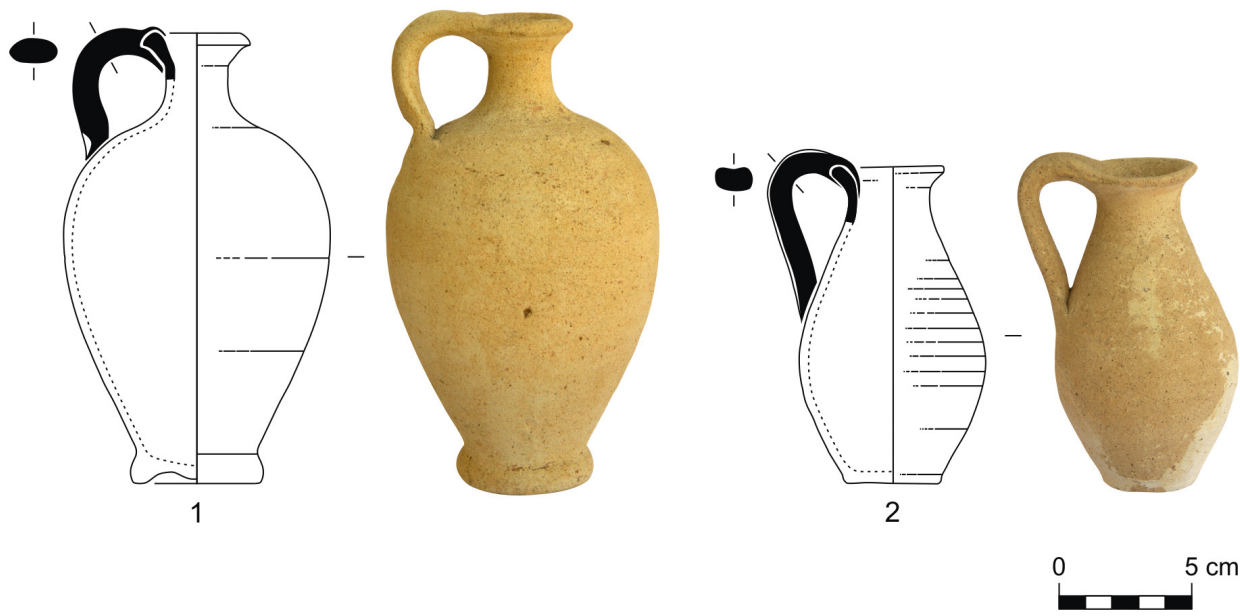

Figura 4. Jarritas de tradición púnica y posible producción local/regional. Necrópolis de Bab-el-Oued (dibujos, A. Quevedo; fotos, M. Bouquet).

\subsection{Cámaras sepulcrales}

Entre las diferentes prácticas funerarias documentadas en Bab-el-Oued, abundan los grandes monumentos sepulcrales. Cerca del Kursaal se encontraron a inicios del siglo xx dos criptas en mampostería, cada una de ellas precedida por un pozo rectangular (Gsell, 1909: CLXXIX-CLXXX). Las cámaras medían 2,52 ×2,40 m y 2,05× 1,98 m, respectivamente. Ambas contaban con una bóveda de cañón y una banqueta que discurría a lo largo de las paredes. La más grande poseía seis nichos en su interior para la colocación de urnas cinerarias. Por desgracia las dos habían sido saqueadas: la primera estaba vacía y la segunda no contenía más que restos de huesos calcinados y algunos fragmentos de vidrio, cerámica común y utensilios de hierro. Una tercera cámara, más grande y con las mismas características constructivas que las anteriores, fue encontrada a proximidad de estas en 1912 (Ballu, 1913: 145-146). El monumento funerario estaba formado por un pasillo de $0,9 \mathrm{~m}$ de longitud dotado de cuatro nichos, a los que se añadían 15 más documentados en el hipogeo principal. El único mobiliario descrito durante el hallazgo es una urna cineraria en cerámica llena de huesos quemados, dos pequeños vasos en cerámica y dos lucernas con la firma C.CLO.SVC. Estas últimas pertenecen al alfarero itálico Caius Clodius Succesus, que desarrolló su actividad entre finales del siglo I y las primeras décadas del siglo II d. C. (Bussière, 2000: 218).

Entre las cámaras sepulcrales de Bab-el-Oued, la más significativa fue descubierta en 1863 -intacta, a 12,50 metros de profundidad-durante los mencionados trabajos de construcción del Grand Lycée (Berbrugger, 1863: 193-204). El edificio funerario conservaba al exterior un basamento cuadrado de 4,22 m, sobre el que debía levantarse el resto 


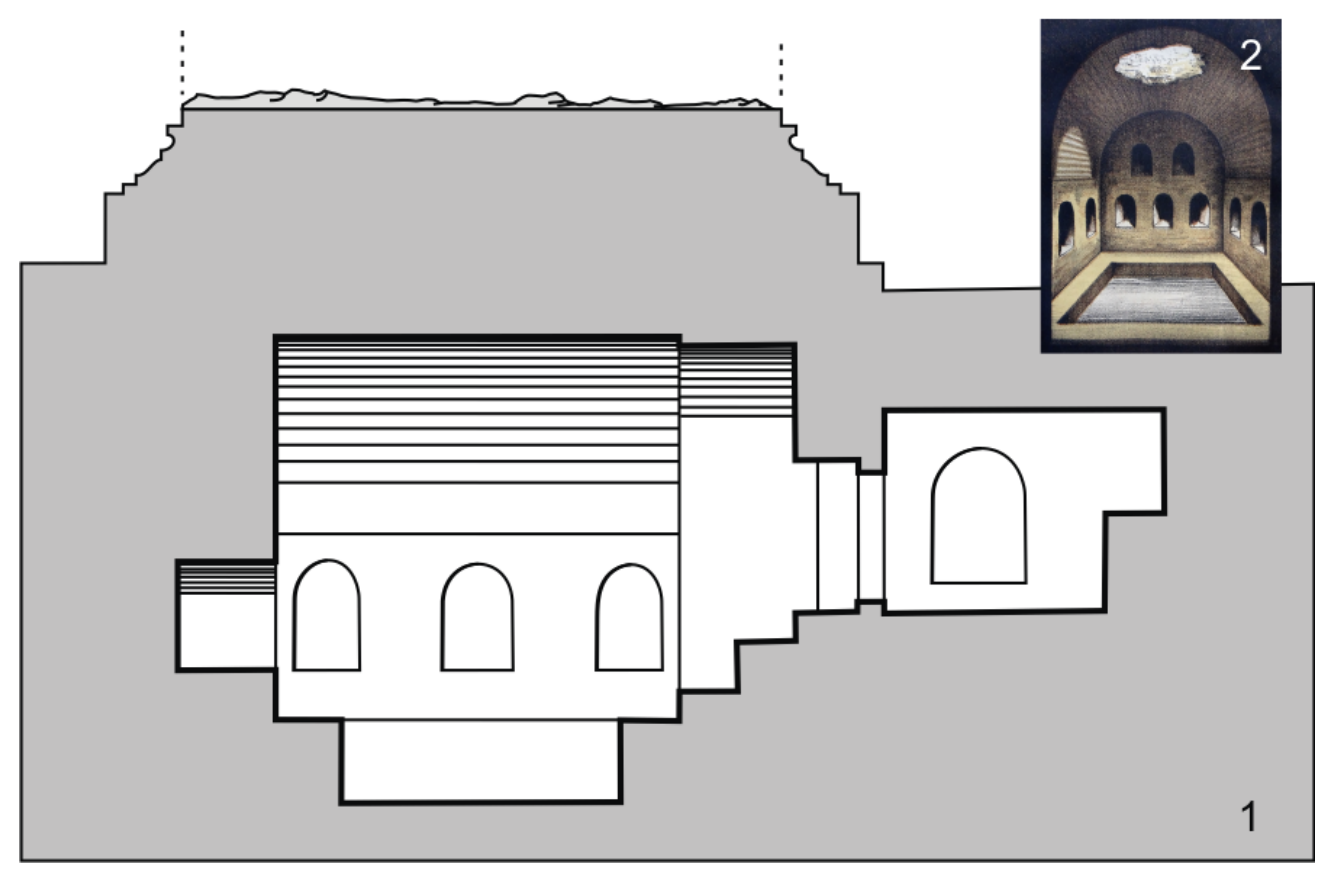

Figura 5. Cámara sepulcral descubierta bajo el Grand Lycée de Argel. 1: Sección longitudinal. 2: Vista frontal en la que se aprecia la subida del nivel freático (Berbrugger, 1863, sin escala; reelaboración, A. Quevedo).

del monumento (fig. 5.1). Bajo el mismo se hallaba la cámara funeraria, donde Berbrugger en persona se introdujo creando una apertura en la bóveda, si bien fue posible excavar la entrada original días después, protegida por un muro de mampostería, y acceder a través de ella. El edificio estaba constituido por un pequeño pasillo con dos nichos para urnas funerarias, una de las cuales, la de la izquierda, había sido cegada. Al final del pasillo, mediante tres escalones, se llegaba a una puerta de piedra de la que aún se conservaban restos del sello, lo cual hace pensar que originalmente estaba cerrada. A través de la misma se accedía a la cámara sepulcral, con una altura de 2,68 m y rematada por una bóveda de cañón. A lo largo del espacio central, de 2,24 m de ancho, corría una banqueta de mampostería, y en las paredes había 13 nichos para urnas. Según las marcas que presentaban los muros, el agua del nivel freático había aumentado hasta alcanzar los nichos, desplazando algunos de los objetos de sitio. De hecho, cuando se abrió la cámara aún contenía agua (fig. 5.2), y el propio Berbrugger (1863) relata cómo algunas piezas flotaban el día del descubrimiento. Aunque se planteó la preservación del monumento mediante la transformación de su zócalo superior en una fuente (Berbrugger, 1863: 204), el proyecto nunca se llevó a cabo.

Se documentaron un total de 33 piezas completas de vidrio soplado y cerámica, varias de las cuales han podido ser identificadas gracias a las descripciones de la época 

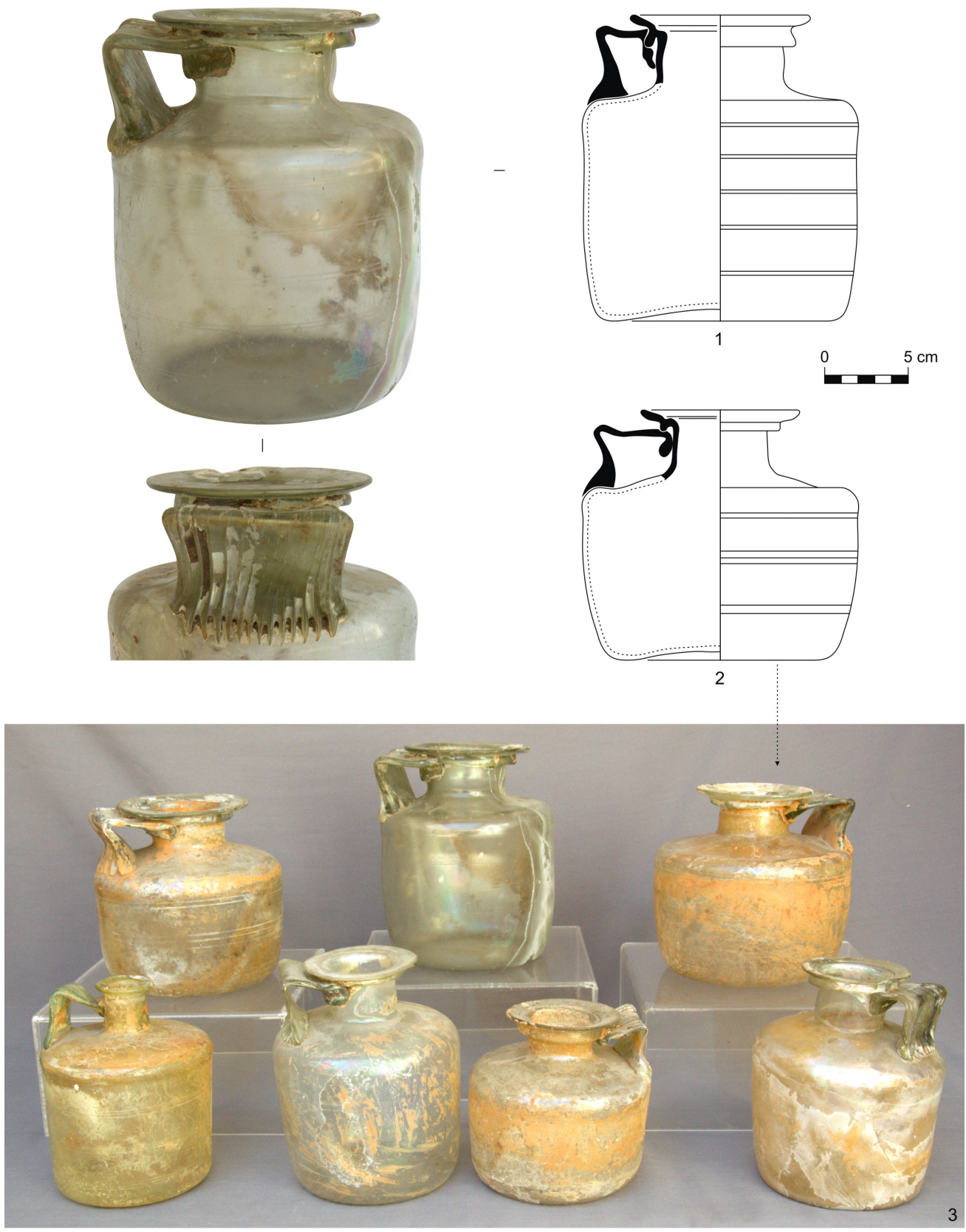

Figura 6. Urnas funerarias en vidrio procedentes de la cámara sepulcral hallada bajo el Grand Lycée de Argel en 1863 (dibujos, A. Quevedo; fotos, M. Bouquet). 

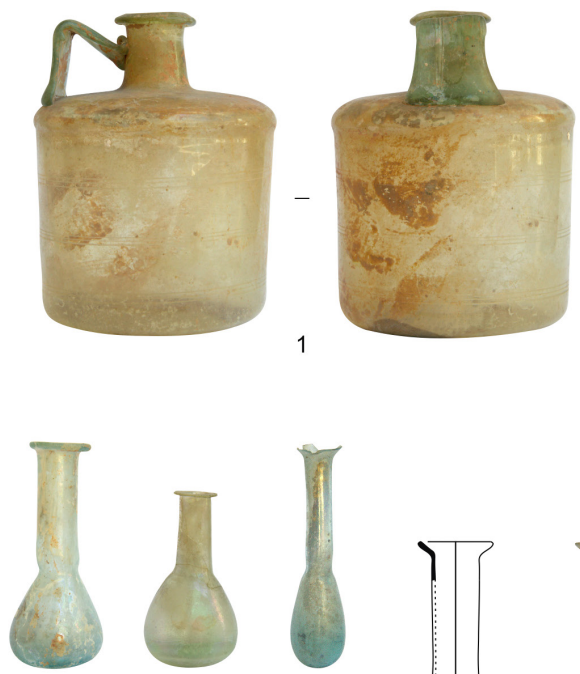

3

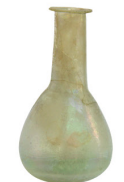

4

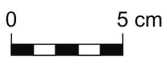

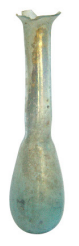

5

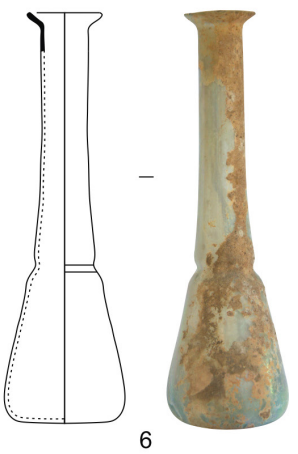

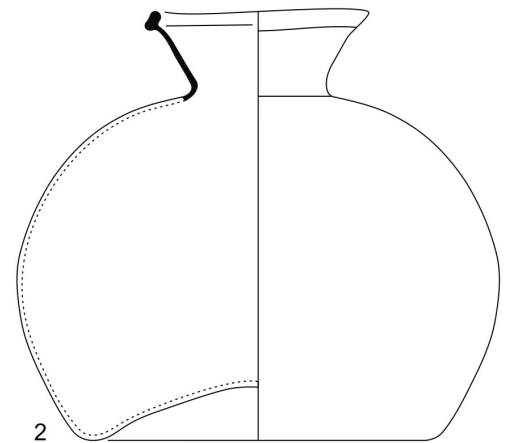

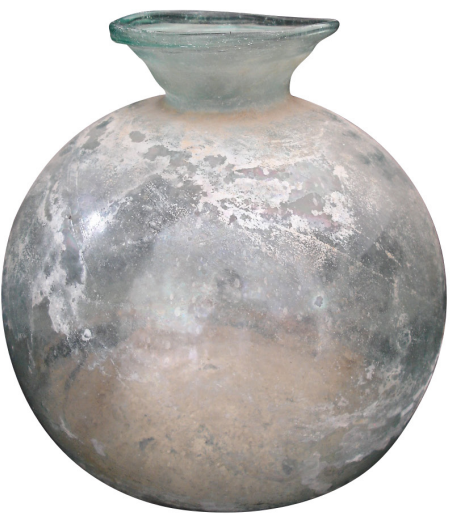

Figura 7. Vidrio de la cámara sepulcral del Grand Lycée de Argel. 1-2: Urnas funerarias. 3-6: Balsamarios (dibujos, A. Quevedo; fotos, M. Bouquet).

(Berbrugger, 1863: 199-203). La única práctica funeraria constatada en el monumento es la cremación, y entre los materiales que se asocian a la misma, la urna de vidrio monoansada Isings 51 a es la más abundante, caracterizada por un cuerpo cilíndrico dotado de algunas incisiones horizontales (figs. 6.1 y 6.2). La forma posee un fondo ligeramente abombado y un cuello corto y ancho. El borde, achatado y exvasado, presenta una moldura en el exterior, y el asa, una nervadura múltiple. Por lo general es un tipo producido en un vidrio transparente con irisaciones verdes y azules, ampliamente representado en Bab-el-Oued (fig. 6.3). A excepción de un ejemplar con el cuello más estrecho (fig. 7.1), el resto de urnas comparten las mismas características. En general, estas piezas se datan a partir de la segunda mitad del siglo I d. C. (Isings, 1957: 67-68; D’Escurac-Doisy, 19661967: 140-143, fig. 1-6). El paralelo más próximo a Argel procede de la tumba 67 bis n. ${ }^{\circ} 13$ de la necrópolis de la Porte de Césarée en Tipasa (Lancel, 1967: 9, 46-47, n. ${ }^{\circ}$ catálogo 49), fechada entre finales de época flavia y el reinado de Marco Aurelio (Lancel, 1970: 155). 
Dentro del conjunto de urnas funerarias resulta especialmente interesante la que se encontraba en el nicho cerrado del pasillo de acceso a la cámara y que contenía huesos calcinados en su interior. Se trata de un unicum cuya identificación ha sido posible gracias a la descripción de la época, en la que fue comparada con una "pecera» (Berbrugger, 1863: 195). La pieza presenta un cuerpo esférico, con cuello en forma de cono invertido acabado en un borde algo más grueso que la pared y ligeramente entrante (D'EscuracDoisy, 1966-1967: 149-151, fig. 31, fotografía 1). El fondo posee un abombamiento muy pronunciado. Es una forma producida en un vidrio incoloro, de tintes azulados (fig. 7.2), para la que no se conocen paralelos. Sin embargo, en el mismo nicho se encontró una lucerna con un águila en el disco y un asa plástica triangular decorada (Berbrugger, 1863: 199), actualmente perdida, que ofrece un terminus post quem para ambas. Se trata del tipo itálico Deneauve VB, fechado en el siglo I d. C., una producción que alcanza su floruit en época flavia (Bussière, 2000: 70-71).

Berbrugger describe también una serie de ampullae y de vasos de vidrio cilíndricos y cónicos de cuello largo, de los que solamente dos tipos han sido identificados: una pieza de perfil troncocónico dotada de un asa (Berbrugger, 1863: 199, n. 4; D’Escurac-Doisy, 19661967: 150-151, fig. 32) y una botella de la forma Isings 51b (Berbrugger, 1863: 199, n. ${ }^{\circ}$; D’Escurac-Doisy, 1966-1967: 149-150, fig. 30), ninguno de los cuales hemos podido revisar personalmente. No obstante, se han localizado en los fondos del MNA cuatro unguentaria de un total de seis hallados en la época. Producidos en vidrio soplado con tintes azulados, se caracterizan por un cuerpo más o menos piriforme, sin pie, y un cuello cilíndrico ligeramente estrangulado en su base, todos ellos vinculados al tipo Isings 28. Los dos primeros pertenecen a la variante Isings 28a, con un borde exvasado y labio achatado (fig. $7.3 \mathrm{y}$ 7.4). El tercero se encuadra en la variante Isings 28 b, de cuerpo troncocónico y cuyo labio, fracturado, parece haber sido cortado y redondeado al fuego (fig. 7.5). El cuarto y último posee las mismas características técnicas que el anterior, pero con una altura de 18,5 cm y un cuerpo más cónico (fig. 7.6). Este tipo de formas se producen a partir del reinado de Claudio y son frecuentes en las necrópolis del occidente del Imperio, especialmente durante la segunda mitad del siglo I d. C., como ponen de manifiesto contextos de referencia del Mediodía galo y de Lyon (Robin, 2016: 164-166, con bibliografía).

El repertorio de las piezas de vidrio de la cámara sepulcral del Grand Lycée se completa con un célebre vaso pintado (Hamelin, 1955): una copa de vidrio soplado, incoloro, pero con un ligero tinte blanquecino. La forma, dotada de un pie, es de perfil ligeramente exvasado, con una carena en su tercio inferior y acabada en un borde vertical con el labio cortado (fig. 8.1). En la parte central del cuerpo, en una franja enmarcada por dos ranuras, se desarrollaba una escena pintada de lucha de gladiadores por parejas, actualmente desaparecida casi por completo. Se trataba de un combate entre un tracio y un samnita y entre un retiarius y un mirmillón. Sobre cada una de las escenas sobrevuela una corona vegetal y ambos grupos están separados por una estatuilla y hojas de palma. Inicialmente la copa se fechó entre los siglos II-III d. C. (Le Glay, 1968: 38, cf. con el tipo 55.2 de Lyon; Robin, 2016: 224-225). Sin embargo, otras piezas con los mismos motivos decorativos se documentan en distintas partes 

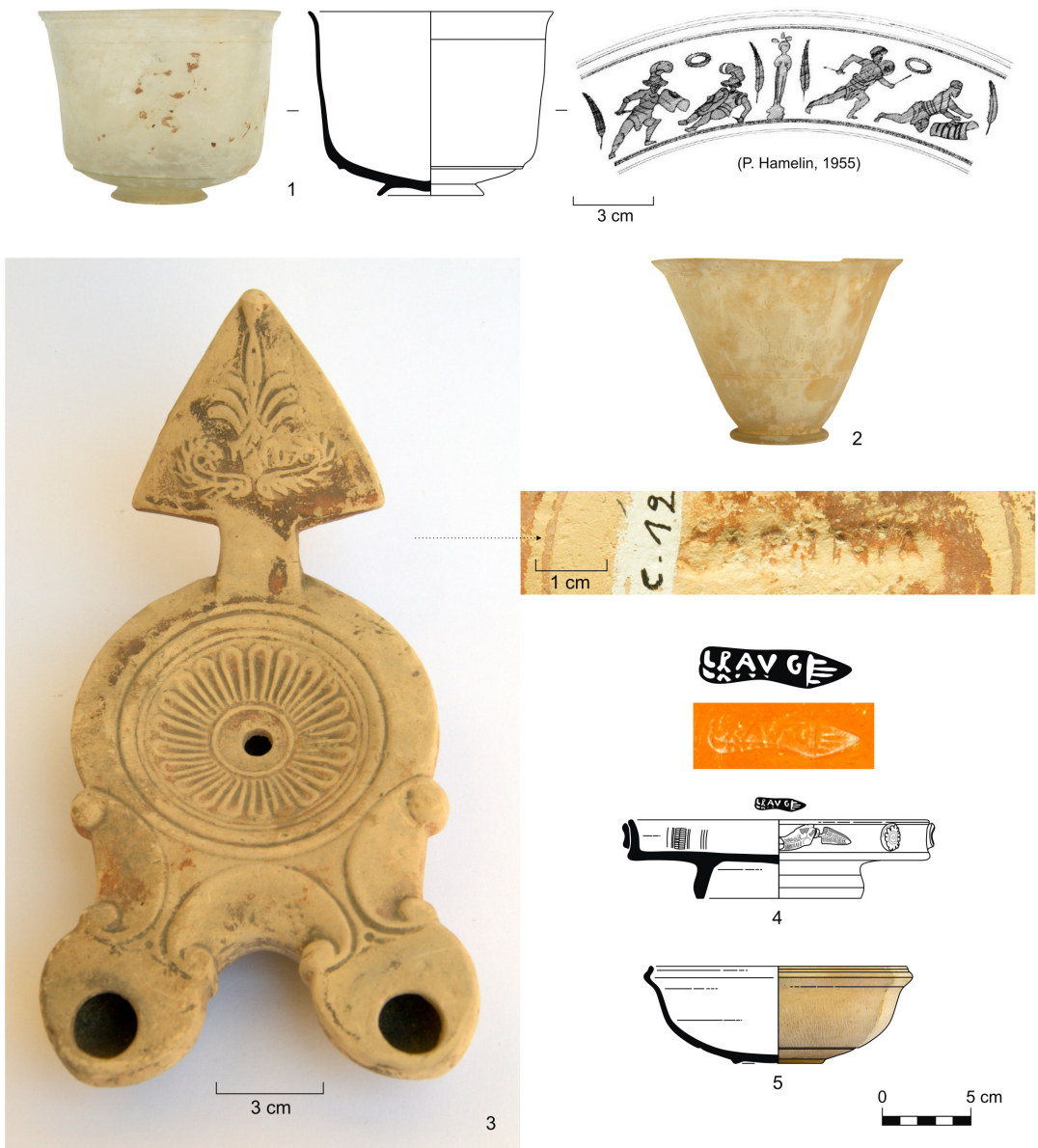

Figura 8. Material funerario de la cámara sepulcral del Grand Lycée de Argel. 1-2: Vasos de vidrio pintados. 3: Lucerna itálica con sello impreso GABINIA. 4: Plato en terra sigillata itálica, sello L.P.AVG. 5: Cerámica de paredes finas (dibujos, A. Quevedo; fotos, M. Bouquet).

del Imperio a partir de Tiberio/Claudio - época flavia (Landes, 1986: 346-347; Foy y Nenna, 2001: 180), motivo por el que, en línea con el resto de objetos del monumento funerario, llevamos su datación hacia la segunda mitad del siglo i d. C. Otra copa pintada en vidrio soplado formaba parte del mobiliario, aunque la decoración mencionada durante su hallazgo (Berbrugger, 1863: 200) haya desaparecido totalmente. Se trata de una pieza en forma de cono invertido que reposa sobre un pie anular creado mediante un repliegue del vidrio (fig. 8.2). La copa muestra una coloración blanquecina que podría deberse a una oxidación del vidrio (D'Escurac-Doisy, 1966-1967: 149, fig. 28). 
A excepción de los ejemplares pintados, posibles importaciones de talleres especializados de Alejandría, Siria o Italia, el resto de piezas podrían proceder de la vecina Tipasa o bien de Caesarea, donde un epitafio del siglo I d. C. hace alusión al vitrarius Saburrius o Saburrio (Leveau, 1984: 69) y, por tanto, a la producción local de vidrio. No cabría asimismo descartar su fabricación en Icosium, si bien por el momento no se han documentado restos que atesten esta actividad en la ciudad.

En lo que respecta al material cerámico, destacan dos lucernas firmadas encontradas en el interior de la cámara sepulcral. Un ejemplar «incrustado» (sic) en el arranque de la bóveda presentaba la firma V.VESECA, según Berbrugger (1863: 198). Desgraciadamente la pieza se perdió, por lo que no ha sido posible revisarla ni contrastar la lectura, con probabilidad errónea, de la marca, para la que no se conoce ningún paralelo. El otro ejemplar, que sí se conserva, es un tipo Deneauve VB, una lucerna de dos picos con forma ojival y un asa plástica triangular, perforada en su base, y decorada por una palmeta de siete brazos y dos volutas de hojas de acanto (fig. 8.3). El disco está decorado por un rosetón de 21 pétalos y en el fondo la pieza presenta el sello impreso GABINIA, típico de entre finales del siglo I y la primera mitad del siglo II d. C. (Pavolini, 1976-1977: 77-82), aunque este tipo de lucernas se produjeron hasta finales del siglo II - inicios del siglo III d. C. (Bussière, 2000: 70-71).

Los datos relativos al resto de formas cerámicas son escasos. En el interior de la cámara aparecieron una serie de platos con sellos in planta pedis (Berbrugger, 1863: 200-201), cuyas características permiten asociarlos a productos en terra sigillata itálica (TSI). Solamente se conserva uno del tipo Conspectus 20.4 decorado al exterior por apliques plásticos: dos guirnaldas enfrentadas y dos rosetas. Está firmado L.P.AVG (fig. 8.4). El sello L. $A V($ ) $G($ ) + P. $A V($ ) $G($ ), cuya producción se sitúa en Italia central, se fecha a partir de los años treinta del siglo i d. C., aunque la cronología de la forma se extiende hasta época de Domiciano (Ettlinger et al., 1990: 86-87; Oxé y Comfort, 2000: 150-151, OCK tipo 361.1). En Argelia se conocen otros ejemplares con la firma LP.AVG (Guéry, 1992: 49, n. ${ }^{\circ}$ 148, 149 [el nuestro] y 150), y un plato idéntico, con la misma decoración, fue hallado en una tumba de Tipasa, junto a un bronce de Galba (Lancel, 1970: 167-168, fig. 14, tumba 553).

Los otros sellos itálicos son CLO.PRO y L.ANN. El primero pertenece a Clodius Proculus, cuya producción se sitúa entre 40-100 d. C. (Oxé y Comfort, 2000: 37-38 y 185). Varios Clodii se mantuvieron muy activos durante el período flavio (para la distribución de Clodius Proculus en Argelia, donde está bien documentado, vid. Guéry, 1992: 64-66, n. ${ }^{2}$ 234-247). El segundo sello corresponde a L. Annius, productor de Arezzo, fechado a partir de otros ejemplares firmados L.ANN E y procedentes de Tipasa hacia mediados del siglo I d. C. (Lancel, 1970: 221; Guéry, 1992: 25, n. ${ }^{\circ}$ 25-29).

En terra sigillata tardoitálica se registra un único sello, L.R.P., cuyas letras están separadas por pequeñas interpunciones en forma de flecha (Berbrugger, 1863: 201). Se trata de Lucius Rasinius Pisanus, conocido productor en TSTI y el mejor representado en territorio argelino (Guéry, 1987: 159-162, n. ${ }^{\circ}$ 63-99 [el nuestro es el n. ${ }^{\circ}$ 93]; para su distribución, vid. p. 184-186, fig. 13). Su cronología se sitúa entre la segunda mitad del siglo i d. C. y las primeras décadas del siglo II d. C. (Huguet, 2007: 120). 
En terra sigillata gálica (TSG) se contarían otros dos sellos documentados en cartelas rectangulares. El primero es ROIPVS.FEC, del productor Roppus (ROPPVS.FEC), fechado a partir de mediados del siglo i d. C., entre 50 y 80 d. C. para Guéry (1979: 72, n. ${ }^{\circ}$ 163; 1987: 174) y no antes del 70 d. C. para Hartley y Dickinson (2011: 402-403, Roppus i). El segundo es [...]LANIM, cuya lectura se mantiene abierta.

Completa el repertorio una forma de paredes finas de grosor especialmente sutil (tan sólo algunos milímetros): un bol de pasta blanquecino-amarillenta decorado a ruedecilla y con el fondo retorneado, para el que no se conoce ningún paralelo (fig. 8.5).

A partir de la datación de los distintos elementos del mobiliario funerario puede proponerse una cronología para la ocupación de la cámara sepulcral entre las últimas décadas del siglo I d. C. y mediados del siglo II d. C. Arquitectónicamente, el paralelo más cercano al mausoleo de Argel es el llamado «monumento K» de la necrópolis occidental de la Porte de Césarée de Tipasa, que además presenta unas medidas muy similares. Los elementos datantes recuperados en su interior, entre los que se encuentra una moneda de Faustina (emperatriz entre 138 y 141), sitúan su utilización hacia mediados del siglo II d. C. (Lancel, 1970: 205-211).

\subsection{Inhumaciones}

En 1862 se descubrieron las primeras inhumaciones en la necrópolis de Bab-el-Oued, que hasta esa fecha se había caracterizado por la presencia exclusiva de cremaciones (Berbrugger, 1862: 31 1-315). Solamente se han conservado los ajuares de dos de esas tumbas.

El primer enterramiento fue hallado en una fosa formada por bloques y una cubierta de ladrillo y tres losas en su interior sobre las que descansaba el cuerpo. El ajuar estaba compuesto, entre otros objetos, por dos platos de vidrio soplado (D'Escurac-Doisy, 1966-1967: 145-148). El primero es un plato tipo Isings 97a en vidrio transparente (Isings, 1957: 117), que se caracteriza por un borde ancho y convexo, dotado de un rodete, terminado en un reborde horizontal obtenido a partir de un pliegue del propio vidrio (fig. 9.1). El fondo, que cuenta con un pie anular constituido igualmente a partir de un pliegue, es ligeramente convexo y presenta un mayor grosor en su parte central. Esta forma, muy frecuente en el Mediterráneo occidental, cuenta con un paralelo en la necrópolis de Tipasa, en una tumba fechada por un as de Trajano (Lancel, 1967: 87-88, n. ${ }^{\circ}$ 175). El segundo plato, de un tono verdoso, pertenece al tipo Isings 43 (Isings, 1957: 43). De perfil exvasado, posee un borde engrosado a cuyo exterior se adhieren dos tiras de vidrio con ondulaciones a modo de elementos de prensión contrapuestos (fig. 9.2). El fondo, marcadamente cóncavo, se apoya en un pie formado por un anillo de vidrio.

En lo que respecta al mobiliario cerámico, Berbrugger (1862: 312) cita la existencia de nueve platos de terre rouge, de los cuales el más grande estaba decorado con hojas de agua sobre el borde. Se trata de una forma Hayes 3A (fig. 9.3), una de las variantes más antiguas de la terra sigillata africana A, fechada en época flavia (Hayes, 1972: 25). Berbrugger no especifica la presencia de marcas de agua sobre otros platos, aunque es muy posible que 

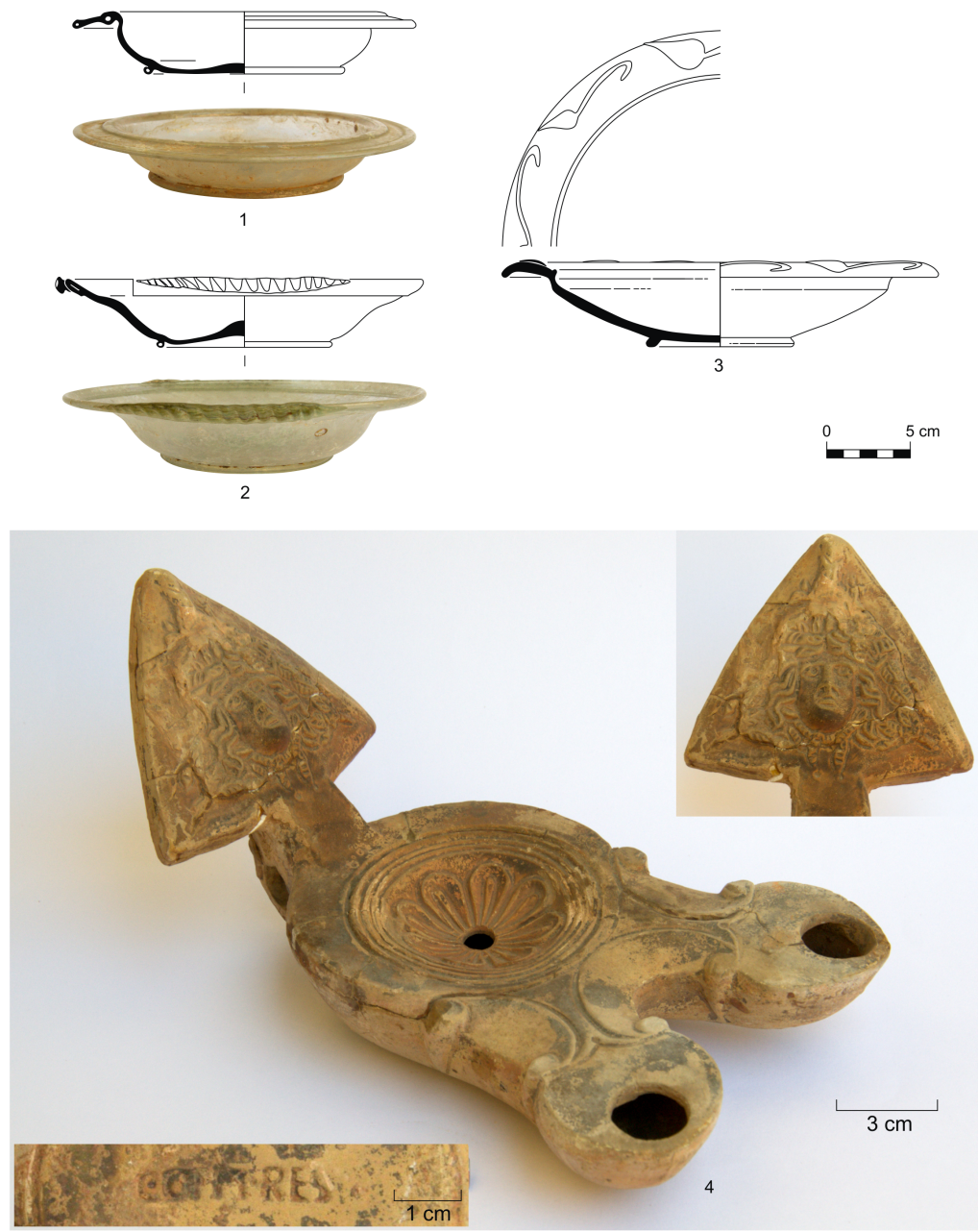

Figura 9. Materiales procedentes de tumbas de inhumación de Bab-el-Oued. 1-2: Platos de vidrio soplado. 3: Cuenco en terra sigillata africana A, forma Hayes 3A. 4: Lucerna itálica de doble piquera con el sello impreso C.OPPI.RES (dibujos, A. Quevedo; fotos, M. Bouquet).

al menos cinco piezas de idéntica tipología y procedentes de Bab-el-Oued pertenezcan a este conjunto (Akkab y Cheniti, 2007: 107-111). Cuatro lucernas completaban el repertorio, una de las cuales, con el disco decorado por una máscara teatral, presentaba el sello impreso L.MVNPHILE en el fondo, leído erróneamente como L.ANIHILE en un primer momento (Berbrugger, 1862: 313). El taller de L. Munatus Phile( ), probablemente itálico pero con una sucursal en el norte de África, estuvo activo entre finales de época flavia y el reinado de Adriano (Casas y Soler, 2006: 54, con bibliografía). 
De la segunda tumba, el único elemento recuperado es una lucerna itálica de grandes dimensiones y doble piquera de forma ojival del tipo Deneauve VB (fig. 9.4). El disco está decorado por una flor de ocho pétalos y un asa plástica triangular con una cabeza de Medusa caracterizada por una abundante melena en la que el cabello y las serpientes no se distinguen con nitidez. Un paralelo con la decoración más definida apareció en Arlés en un contexto de la segunda mitad del siglo I d. C. (Robin Petitot, 2000: 68, n. ${ }^{\circ}$ cat. 203). En cuanto al fondo, presenta el sello impreso C.OPPI.RES, uno de los principales productores de lucernas del Imperio, activo entre el reino de Domiciano y la primera mitad del siglo II d. C. (Bussière, 2000: 228-229). Entre el resto de objetos que formaban parte de este lote, cabe citar un plato, probablemente en sigillata itálica, decorado al exterior con cuatro cabezas, guirnaldas y genios alados, con el sello C.IVL[...] (Guéry, 1979: 57, n. ${ }^{\circ}$ 73).

En Bab-el-Oued, la cremación y la inhumación cohabitaron en los primeros siglos del Imperio. Se trata de un fenómeno que no ha de ser considerado excepcional de esta época, como muestran los ejemplos de las cercanas necrópolis de Tipasa (Février, 1991: 184-185) y Caesarea (Leveau, 1976), aunque la inhumación se convertirá en la práctica dominante a partir del siglo III d. C. Esta coexistencia queda demostrada por el uso contemporáneo de lucernas firmadas C.CLO.SVC, GABINIA o C.OPPI.RES en cámaras sepulcrales y enterramientos. Estos sellos no circulan antes del 80 d. C. - -aunque aparecen en lucernas de volutas, consideradas más antiguas, no hay evidencia de los mismos en Pompeya (Pavolini, 1976-1977: 77-82)—, lo que ofrece igualmente un terminus post quem para el desarrollo de la necrópolis. El resto del material y los paralelos de yacimientos de referencia como Cherchell y Tipaza (Baradez, 1968, 1969) permiten prolongar la ocupación de este espacio funerario hasta mediados del siglo II d. C.

\section{Pervivencia de la necrópolis durante la Antigüedad tardía}

La necrópolis de Bab-el-Oued se mantiene activa hasta, al menos, mediados del siglo II d. C., como confirma, además de la revisión de los ajuares, el único elemento epigráfico conservado que aporta referencias cronológicas (Gsell, 1909: CLXXX). Se trata de la mencionada inscripción del soldado Titus Flavius Sextus (fig. 10.1):

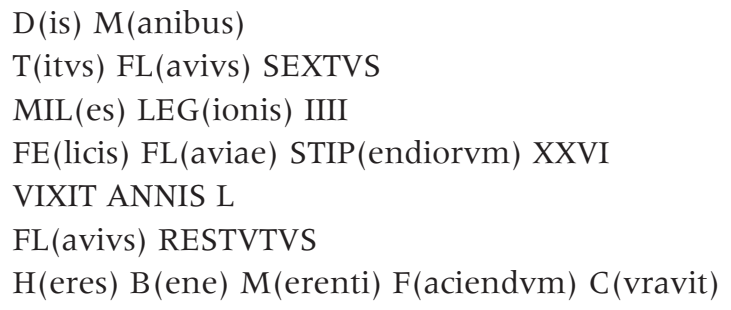




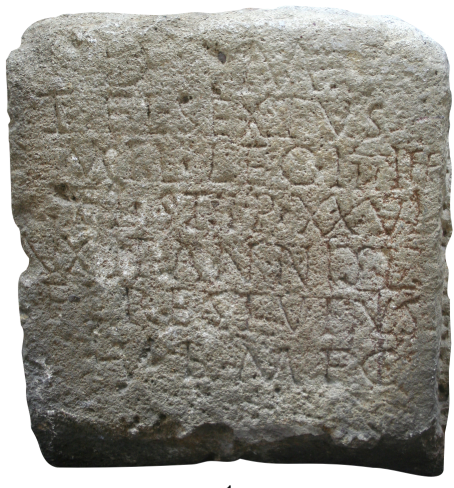

1
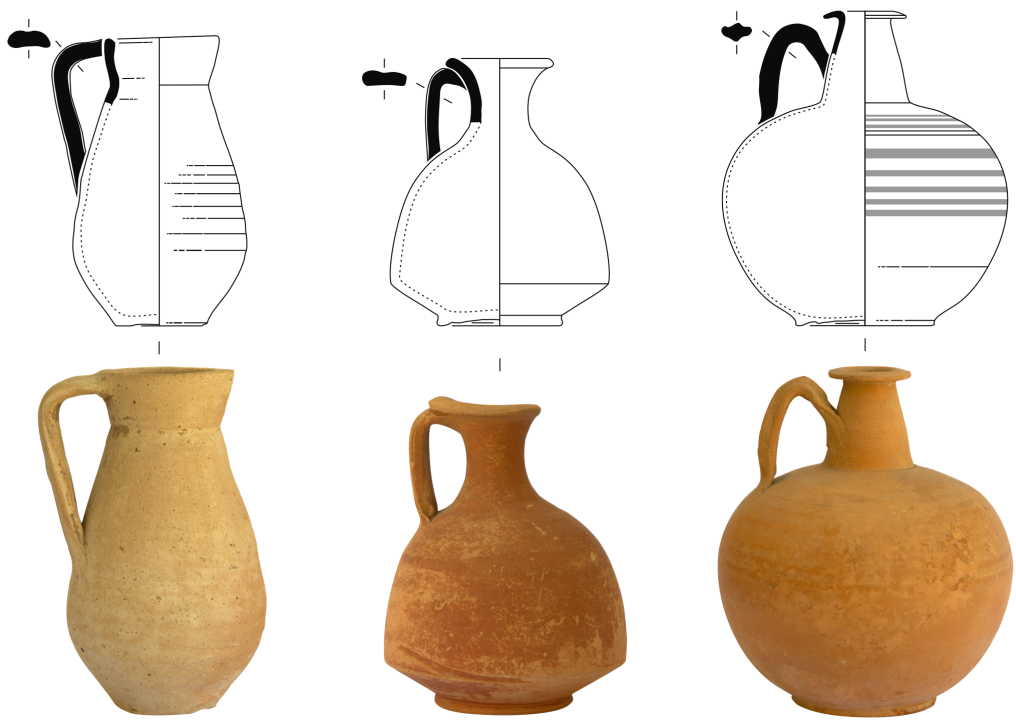

।

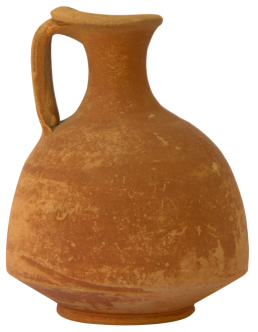

3

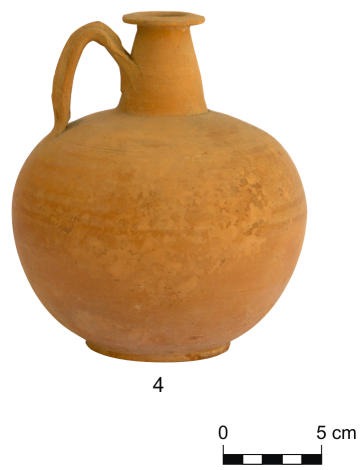

Figura 10. 1: Inscripción de Titus Flavius Sextus, soldado de la legio IV Flavia Felix (foto, N. Benseddik). 2-4: Materiales de los siglos ॥-III d. C. de origen africano (2-3) e hispánico (4) procedentes de la necrópolis de Bab-el-Oued (dibujos, A. Quevedo; fotos, M. Bouquet).

La legio IV Flavia Felix, destinada a la frontera danubiana, pudo operar en Mauretania Caesariensis bajo el reinado de Antonino Pío (Le Glay, 1968: 32; Le Bohec y Wolff, 2000: 239-242; Akkab y Cheniti, 2007: 120). A partir de dicho momento la información sobre esta vasta zona funeraria se vuelve mucho más limitada, siendo la única referencia numismática que se conoce para el siglo III d. C. una moneda del emperador Claudio II el Gótico (268-270 d. C.) encontrada en una tumba (Devoulx, 1875: 497). 
A pesar de que no existen datos sobre las modalidades de enterramiento en la necrópolis septentrional de Icosium entre los siglos II y III d. C., se conservan algunos objetos que pertenecen a esta horquilla cronológica y que proceden con seguridad del yacimiento, si bien no es posible asociarlos a tumbas concretas. Destaca una jarra de cuerpo piriforme, fondo plano y cuello troncocónico del tipo Bonifay 50 (Bonifay, 2004: 285), de pasta calcárea, jabonosa al tacto y color beige-amarillento con inclusiones ocres (fig. 10.2). Es una forma muy frecuente en las necrópolis de Tipaza y Cherchell, lo que hace pensar en la posibilidad de que se trate de una producción mauritana (Quevedo, 2019: 69). Otras formas cerradas podrían pertenecer igualmente a este horizonte, como una jarra con carena baja, cuello exvasado y un asa. El fondo, con huellas de retorneado, acaba en un pie anular, mientras que el borde está fuertemente erosionado (fig. 10.3). La superficie está cubierta por un engobe rojo oscuro que deja entrever una pasta anaranjada. La pieza recuerda a la jarra tipo XXI de Sétif, encontrada en un contexto funerario de los siglos II-III d. C. (Guéry, 1985: 147 y 355, Pl. XLV, 1 17b). A esta misma cronología se vincula una última jarra de perfil esférico, dotada de un pie anular y un asa, con el cuello cónico y el borde achatado al exterior. Presenta además diversas bandas pulidas en su superficie externa (fig. 10.4). Es una forma en cerámica común oxidante del sudeste hispánico, producida con probabilidad en la región de Elche-Cartagena (Quevedo, 2015: 78, fig. 45.4), que también se fabricó en TSA A en el siglo II d. C. (Ripoll y Martí, 1968: 278-279, fig. 2-2 bis = tipo Atlante 20.12).

Aunque la historiografía tradicional fijaba el siglo III como último momento de actividad de la necrópolis (Le Glay, 1968: 38), la existencia de una fase más tardía ya había sido sugerida en 1868 a partir del descubrimiento de una tumba de inhumación con cobertura de tegulae (Berbrugger, 1868: 406-407), al que se añadieron en 1912 otros hallazgos de las mismas características (Gsell, 1909: CLXXIX-CLXXX). El MNA conserva un lote de material funerario de Bab-el-Oued de cronología indudablemente tardía que permite retomar esta hipótesis. A este horizonte pertenece un vaso con carena baja, fondo plano y borde redondeado, no diferenciado, ligeramente exvasado (Akkab y Cheniti, 2007: 104). Una pequeña fractura en su superficie deja entrever una pasta de un color entre rojo ladrillo y marrón oscuro que contiene esquisto y cuarzo anguloso (fig. 11.1) y que recuerda a la de la cerámica de cocina de Mauretania Caesariensis o CMC. Esta producción de posible origen local o regional se documenta ampliamente en los contextos de la zona entre los siglos IV-v d. C., donde aparece en abundancia (Quevedo, 2019: 71-73). En lo que respecta al vidrio se cuenta una botella esférica Isings 103 de color blanco y opaco, con cuello corto estrangulado en su base y reborde cortado y sin labio (fig. 1 1.2). La forma se conoce a partir de la segunda mitad del siglo III d. C., pero es típica del siglo IV d. C. (Isings, 1957: 121122). También hay un vaso troncocónico de color verde y fondo ligeramente cóncavo, con una protuberancia externa a la altura del borde y con el labio cortado (D'Escurac-Doisy, 1966-1967: 148, fig. 234), próximo al tipo Isings 106 (fig. 11.3). Un paralelo — decoradohallado en el pecio Port-Vendres I se fecha entre finales del siglo IV e inicios del siglo $\mathrm{v} \mathrm{d}$. C. (Isings, 1957: 126-129; Foy y Nenna, 2001: 30-31, fig. 19). Completa la lista de objetos en vidrio una copa hemisférica de borde vertical con algunas concreciones calcáreas en 
su interior (D'Escurac-Doisy, 1966-1967: 145, fig. 17). El vidrio, de color azul-verdoso, es espeso y el borde está cortado (fig. 11.4), características ambas que recuerdan a las de formas tardías como las descritas anteriormente. Asimismo, se vincula a este horizonte tardío una copa de perfil ovoide y pie troncocónico, con el borde ligeramente exvasado y producida en un vidrio de tonos verdes (D'Escurac-Doisy, 1966-1967: 148, fig. 25; Akkab y Cheniti, 2007: 131).

Por último, conviene señalar la existencia de un peine parcialmente conservado (fig. 11.5). Descrito como un objeto de marfil (Akkab y Cheniti, 2007: 115), en realidad está fabricado en hueso. Una noticia de Berbrugger (1862: 315) vincula directamente el hallazgo a las inhumaciones tardías de Bab-el-Oued. El peine está formado por una plaqueta rectangular doblemente dentada, siendo los dientes de un lado más anchos que los del otro. Los extremos de la misma están recortados de forma redondeada y sinuosa, con dos perforaciones a cada lado. En la parte central de la plaqueta se fijan dos elementos de prensión rectangulares mediante pequeños remaches de bronce (de los que se conservan cinco). Están decorados por dos incisiones paralelas en su parte superior e inferior y varios círculos concéntricos. Este tipo de objetos, relativamente comunes en la zona centroeuropea, apenas se documentan en el norte de África (¿origen vándalo?), fechándose a partir de los siglos IV-v d. C. (Petitjean, 1995: 160-161, Pl. VII.2-20).

Los elementos mencionados se encuentran en las necrópolis tardías de la zona central de Argelia, caracterizadas por el predominio de las inhumaciones y el uso de ricos ajuares funerarios. El ejemplo más significativo en relación con el caso que nos ocupa es el de Draria-el-Achour, un espacio cementerial situado a escasos kilómetros de Argel (Camps, 1955). En esta necrópolis, fechada en los siglos IV-V d. C., se recuperaron, entre otras formas, distintos platos en terra sigillata africana, probablemente de la categoría D, y formas de cocina en CMC. Su ausencia en Bab-el-Oued puede deberse al azar de los hallazgos arqueológicos o al modo en que se constituyeron las colecciones antiguas del MNA. En cualquier caso, el material estudiado parece confirmar el funcionamiento de la necrópolis en época tardía, si bien el reducido número de hallazgos no permite realizar consideraciones de mayor calado o vincular los ajuares a tumbas concretas.

En lo que respecta a los orígenes del cristianismo en la ciudad, la existencia de tres obispos icositanos relatada por las fuentes muestra que esta no escapó al famoso cisma que desgarró a la Iglesia africana en los siglos IV y v d. C. (Le Glay, 1987: 458-459). Se trata de Crescens, donatista que participó en la conferencia de Cartago en 411; Laurentius, católico presente en la lista de los 217 obispos convocados en Cartago en 418, y Víctor, obispo bajo la dominación vándala que habría asistido al concilio de Cartago organizado en 484 por el rey vándalo Hunerico (Notitia prouinciarum et ciuitatum Africae, Mauret. Caes., 59.). Asimismo, es posible que Icosium recibiera la visita de una figura tan influyente como san Agustín en su camino hacia Cesarea. La presencia de capiteles y de una fenestella confessionis, fechados entre los siglos v y VI, certifica la existencia de edificios de culto cristiano en ese momento. El geógrafo árabe del siglo XI Al-Bakri, impresionado por las ruinas antiguas de Argel, mencionó en particular los restos de una vasta iglesia, que A. Berbrugger vinculaba 

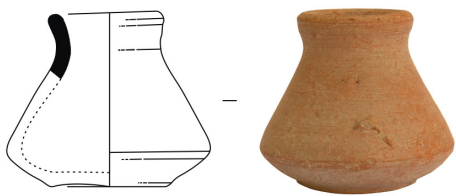

1
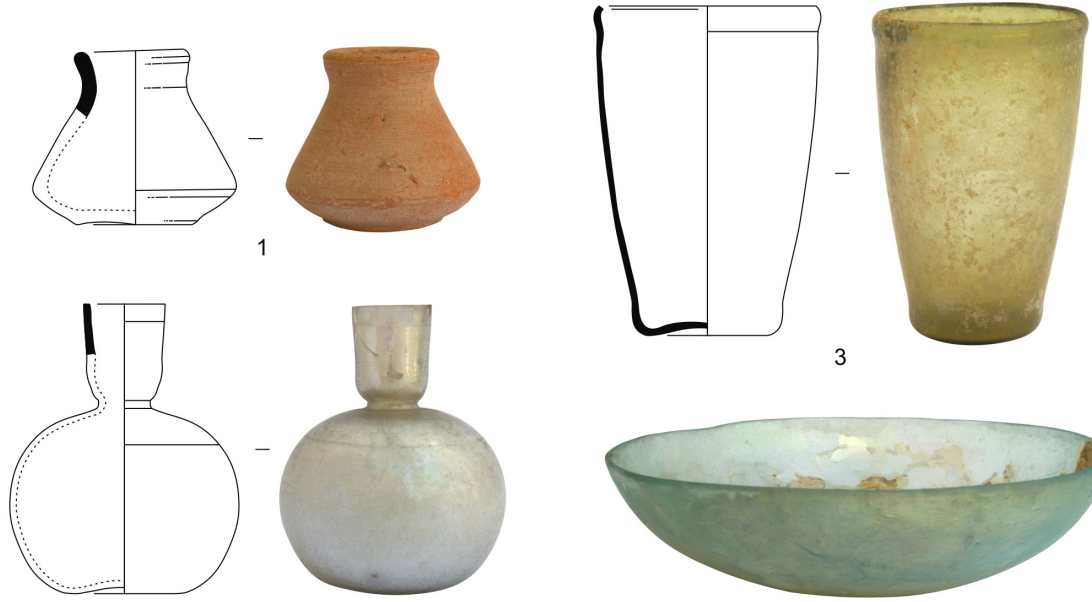

3

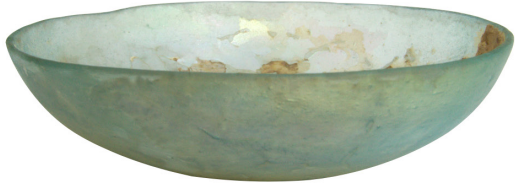

4

2
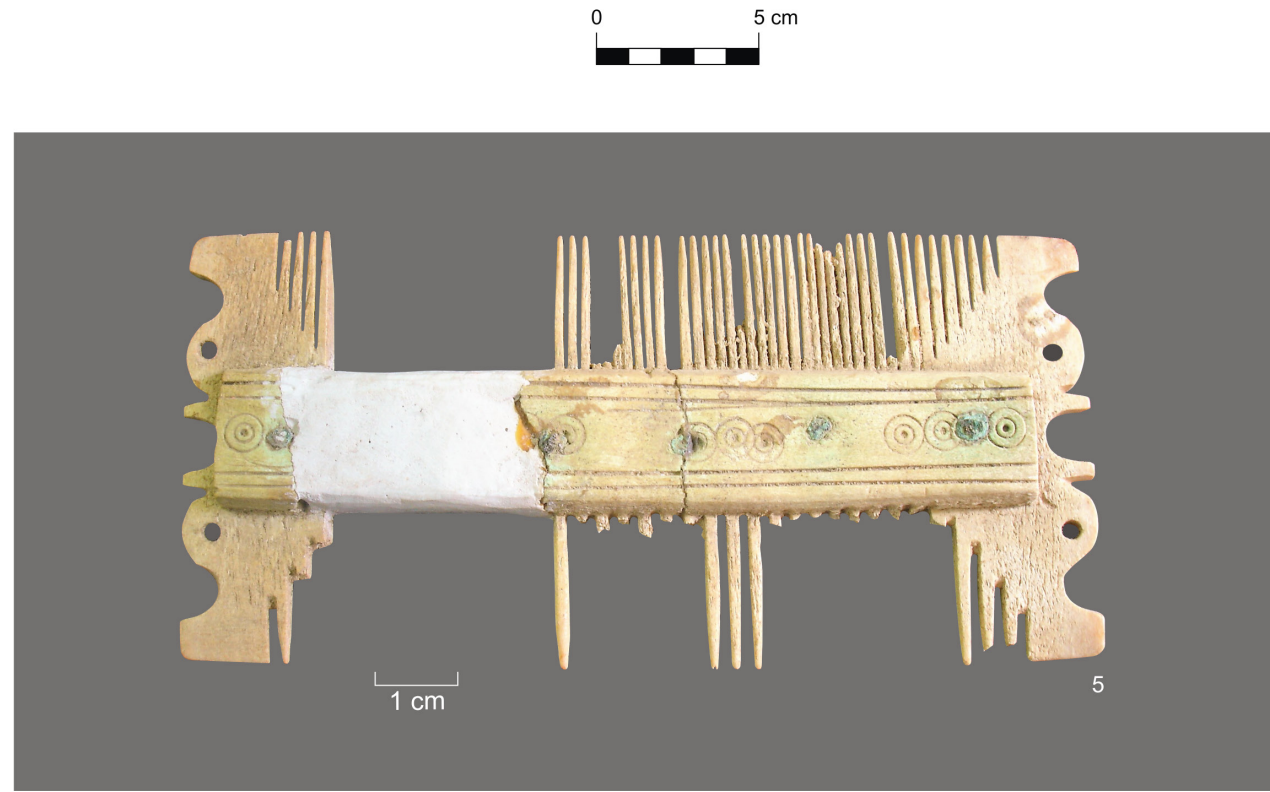

Figura 11. Ajuares tardíos (siglos iv-v d. C.) procedentes de tumbas de inhumación de la necrópolis de Bab-el-Oued (dibujos, A. Quevedo; fotos n. ${ }^{\circ}$ 1-4, M. Bouquet; foto n. ${ }^{\circ}$ 5, MNA).

a los descubiertos cerca de la Gran Mezquita (Berbrugger, 1845: 25). A la espera de la publicación científica sobre la excavación realizada para la construcción del metro en Sahet echouada, resulta difícil establecer un vínculo entre dicha iglesia y una basílica identificada en esta última intervención. Sobre el pavimento de mosaico de la misma aparecieron 71 
tumbas excavadas, la mayoría de inhumación, orientadas este-oeste ${ }^{2}$. Dispuestas en hileras y cubiertas por grandes lajas de arenisca, apenas conservan elementos de ajuar y se fechan en el siglo viI d. C., siendo la necrópolis bizantina de Cartagena uno de sus paralelos más próximos (Madrid y Vizcaíno, 2006).

\section{Conclusión}

La revisión del mobiliario funerario de Bab-el-Oued y de la documentación recogida por A. Berbrugger en el siglo XIx ha permitido corregir las hipótesis de Marcel Le Glay (1968), que fechaba la necrópolis entre finales del siglo in e inicios del siglo in d. C., y distinguir nuevas fases de ocupación. Algunos hallazgos antiguos en CPB sugieren la posibilidad de una primera frecuentación ya entre los siglos III-I a. C., aunque no será hasta el último cuarto del siglo I d. C. cuando tendrá lugar el desarrollo de este espacio funerario del norte de Argel. La mayor parte del material recuperado pertenece a esta fase, fechada entre finales del siglo i d. C. y la primera mitad del siglo II d. C. La práctica predominante es la cremación -las urnas que contienen los restos aparecen a menudo en el interior de grandes cámaras sepulcrales-, aunque también se detectan algunas inhumaciones. Las áreas cementeriales de la cercana Tipasa ofrecen numerosos paralelos para los ajuares y alguno de los monumentos funerarios estudiados. Resulta tentador ligar la expansión de la necrópolis a la concesión del derecho latino a Icosium por parte de Vespasiano, fenómeno que se acompaña de un incremento de la documentación epigráfica en la ciudad. Sin embargo, en Tipaza, donde las tumbas presentan la misma cronología, este privilegio ya había sido concedido anteriormente por Claudio (Plinio, $N H: \mathrm{V}, 2,20$ ). A pesar de que la historiografía tradicional consideraba que la necrópolis de Bab-el-Oued no se mantenía en uso más allá del siglo III d. C., el análisis de algunos objetos en vidrio, cerámica y hueso recuperados permiten vislumbrar su continuidad como espacio funerario entre finales del siglo iv y la primera mitad del siglo v d. C. En época tardía el modo de enterramiento dominante es la inhumación, como confirma la cercana necrópolis de Draria-el-Achour. La existencia en estas mismas fechas de hasta tres obispos muestra la vigencia de la comunidad cívica icositana, aunque el urbanismo tardoantiguo de la ciudad continúe siendo un gran desconocido.

El volumen de material estudiado es demasiado exiguo como para plantear un análisis económico de calado, si bien la heterogeneidad de las producciones muestra una apertura a los principales mercados del momento. Durante la fase altoimperial se constatan los vínculos con Italia a través de la llegada de lucernas y terra sigillata. También destaca la importación de vajilla fina gala y africana y de productos más exclusivos como las copas de vidrio pintadas. Las producciones de la península ibérica apenas se hacen eco, a

2. https://www.inrap.fr/place-des-martyrs-4293 (2009-2017). 
excepción de una botella en cerámica común de la región de Cartagena-Elche, si bien las ánforas hispanas ocupan destacados porcentajes en otros contextos altoimperiales de la región como los de Cherchell y la villa rustica de Nador (Quevedo, 2019: 65-66, fig. 3.1). Asimismo, cabe reseñar la presencia de piezas de cerámica común de producción local o regional y de abundante vidrio, para el que no hay que descartar un origen autóctono dada la originalidad de algunas formas y la existencia de artesanos especializados en la cercana capital provincial. Numerosas incógnitas se mantienen abiertas, en especial para la fase tardía. Los datos existentes no permiten discernir si la escasez de material ha de traducirse en una menor densidad de ocupación. Es posible que el fenómeno tenga que ver con el modo en que se formaron las colecciones del museo o con el hecho de que las tumbas tardías fuesen menos ricas que las de la etapa precedente.

Mediante la revisión de los ajuares excavados hace más de un siglo se han podido matizar algunos aspectos concernientes al desarrollo de la necrópolis de Bab-el-Oued. Las lagunas documentales han sido compensadas en parte por unas piezas en extraordinario estado de conservación que, además de enriquecer la panoplia funeraria de la época, se mantienen como el único testimonio de un vasto sector periurbano de Icosium ya desaparecido. Los datos obtenidos revelan el interés que conlleva el estudio de antiguos materiales, la única vía, junto con nuevos trabajos de excavación, de profundizar en el conocimiento de la Argel romana.

\section{Agradecimientos}

Trabajo realizado en el marco del proyecto «TIPASA. Ocupación, producción y relaciones de interdependencia en el territorio de una ciudad africana durante la Antigüedad (T002020N0000045517)", financiado por el Ministerio de Cultura del Gobierno de España y la «Misión arqueológica hispano-argelina en Tipasa: explorando el antiguo territorio de una ciudad africana Patrimonio de la Humanidad», financiada por la Fundación Palarq. Vaya nuestro más sincero agradecimiento a las directoras del MNA, Houria Cherid y, a partir de 2016. Hadja Boukhames; a la antigua jefa del Departamento de Antigüedades, Amel Soltani, y a la siempre infalible Nadia Acheroufene, así como al resto del equipo de conservadores del museo por sus atenciones a la hora de permitirnos consultar el material. También a Isabelle Bertrand (Musées de Chauvigny) por sus interesantes sugerencias en relación con el peine de hueso. Last, but not least, un agradecimiento muy especial a Mathilde Bouquet por haberse ocupado de la documentación fotográfica y a Isabelle Commandré, compañera de fatigas argelinas. 


\section{Bibliografía}

AA. VV., 2014, Trésors du Musée Public National des Antiquités, Musée Public National des Antiquités, Argel.

ABDELOUAHAB, N. y BENSEDDIK, N., 2011, À propos de nouvelles mosaïques d'Algérie, Actes $d u$ Xe colloque sur la mosaïque gréco-romaine (CMGR), Conímbriga, 531-540.

AKKAB, M. T. y CHENITI, M. E. B. (eds.)., 2007, D'Ikosim à El Djazaïr. Catalogue de l'exposition, Musée des Antiquités, Ministère de la culture, Argel.

BALLU, A., 1913, Rapport sur les fouilles exécutées en 1912 par le service des monuments historiques de l'Algérie, Bulletin du Comité des Travaux Historiques et Scientifiques, 145-146.

BARADEZ, J., 1957, Tipasa. Ville antique de Maurétanie, Argel.

BARADEZ, J., 1968, Les nécropoles de Tipasa : Tombes du cimetière occidental côtier, Antiquités africaines 2, 77-93.

BARADEZ, J., 1969, Nécropole orientale côtière de Tipasa de Maurétanie, Antiquités africaines 3, 83-113.

BENSEDDIK, N. (ed.)., e. p., Ikosim-Icosium. Monographie archéologique de la cité antique d'Alger.

BENSEDDIK, N., 2000, L'armée française en Algérie: "Parfois détruire, souvent construire", L'Africa romana 13, Atti del XIII Convegno di Studio sull'Africa Romana, Djerba 1998, Roma, 759-796.

BENSEDDIK, N., 2004, Chronique d'une cité antique, en N. CHABBI-CHEMROUK, N. DJELAL-ASSARI, N. SAFAR ZEITUN y R. SIDI BOUMEDINE (eds.), Alger. Lumières sur la ville, Actes du colloque international tenu à Alger le 4, 5 et 6 Mai 2000, Argel, 29-34.

BERBRUGGER, A., 1845, Notice sur les antiquités romaines d'Alger, Ed. Bourget.

BERBRUGGER, A., 1862, Chronique, Revue Africaine 6, 311-315.
BERBRUGGER, A., 1863, Note sur le tombeau et la chambre sépulcrale découverts les 16 et 22 juin 1863 sur l'emplacement du nouveau lycée, Revue Africaine 7, 193-204.

BERBRUGGER, A., 1868, Nécropole d'Icosium, Revue Africaine 12, 406-408.

BERBRUGGER, A., 1875, Tombeaux, Revue Africaine 19, 389-414.

BONIFAY, M., 2004, Études sur la céramique romaine tardive d'Afrique, British Archaeological Reports, Int. Ser. 1301, Oxford.

BUSSIÈRE, J., 2000, Lampes antiques d'Algérie, Monographies Instrumentum 16, Montagnac.

CAMPS, G., 1955, La nécropole de Draria-elAchour, Lybica. Archéologie-Épigraphie 3, 255-264.

CASAS, J. y SOLER, V., 2006, Llànties romanes d'Empúries. Materials augustals $i$ alto-imperials, Monografies Emporitanes 13, Girona.

CINTAS, P., 1948, Fouilles puniques à Tipasa, Revue Africaine 92, 263-330.

CINTAS, P., 1950, La céramique punique, Publications de l'Institut des hautes études de Tunis 3, París.

DESANGES, J., DUVAL, N., LEPELLEY, Cl. y SAINT-AMANS, S. (coord.), 2010, Carte des routes et des cités de l'est de l'Africa à la fin de l'antiquité, Nouvelle édition de la carte des "Voies romaines de l'Afrique du nord " conçue en 1949, d'après les tracés de Pierre Salama, Bibliothèque de l'Antiquité Tardive 17, Brepols.

D'ESCURAC-DOISY, H., 1966-1967, Verrerie antique et collections du Musée National des Antiquités d'Algérie, Bulletin d'Archéologie Algérienne II, 129-158.

DEVOULX, A., 1863, Les édifices religieux de l'ancien Alger. Quartier Bab-el-Oued extérieur, Revue Africaine 7, 102-113.

DEVOULX, A., 1875, Alger. Étude archéologique et topographique sur cette ville aux époques 
romaine (Icosium), arabe (Djezaïr BeniMaz'renna) et turque (El-Djezaïr), Revue Africaine $19,289-429$ y $497-532$.

DUMASSY, F., 2016, Déposséder la ville. Alger au début des années 1830, en Z. RAHMANI y J.-Y. SARAZIN (dir.), Made in Algeria. Généalogie d'un territoire, Mucem, Marsella.

ETTLINGER, E., HEDINGER, B., HOFFMAN, B., KENRICK, Ph. M., PUCCI, G., ROTH-RUBI, K., SCHNEIDER, G., VON SCHNURBEIN, S., WELLS, C. M. y ZABEHLICKY-SCHEFFENEGGER, S., 1990, Conspectus formarum terrae sigillatae italico modo confectae, Dr. Rudolf Habelt GMBH, Bonn.

FÉVRIER, P.-A., 1991, Incinérations et inhumations dans le Maghreb antique, en M. VIDAL (ed.), Incinérations et inhumations dans l'Occident romain aux trois premiers siècles de notre ère (France, Espagne, Italie, Afrique du Nord, Suisse, Allemagne, Belgique, Luxembourg, Pays-Bas, GrandeBretagne), Actes du Colloque International de Toulouse-Montréjeau (IVe Congrès Archéologique de Gaule Méridionale), 7-10 octobre 1987, Toulouse, 181-189.

FOY, D. y NENNA, M.-D., 2001, Tout feu, tout sable. Mille ans de verre antique dans le Midi de la France, Musée d'Histoire de Marseille, Aix-en-Provence.

GSELL, S., 1909, Bulletin archéologique du Comité des travaux historiques et scientifiques, CLXXIX-CLXXXI.

GSELL, S., 1911, Atlas archéologique de l'Algérie, Argel-París.

GUÉRY, R., 1979, Les marques de potiers sur terra sigillata découvertes en Algérie, I, Sigillées provinciales (hispanique et gallo-romaine), Antiquités africaines 13, 23-97.

GUÉRY, R., 1985, La nécropole orientale de Sitifis (Sétif, Algérie). Fouilles de 1966-1967, Études d'Antiquités Africaines, Éditions du CNRS.

GUÉRY, R., 1987, Les marques de potiers sur terra sigillata découvertes en Algérie, II, Sigillée tardoitalique, Antiquités africaines 23, 149-191.

GUÉRY, R., 1992, Les marques de potiers sur terra sigillata découvertes en Algérie, IV, Sigillée italique, Antiquités africaines 28, 15-131.
HAEDO, D., 1927-1929 [1612], Topografía e historia general de Argel, Edición de la Sociedad de Bibliófilos Españoles, 5 vol., Madrid. [A partir del original: Topographia e Historia general de Argel, repartida en cinco tratados do se veran casos estraños, muertes espantosas y tormentos esquisitos, que conviene se entiendan en la Cristiandad: con mucha doctrina y elegancia curiosa, Valladolid, 1612]

HAMELIN, P., 1955, Gobelet de verre émaillé du Musée d'Alger, Libyca. Archéologie-Épigraphie 3, 87-99.

HARTLEY, B. R. y DICKINSON, B. M., 2011, Names on terra sigillata. An index of maker's stamps O signatures on Gallo-Roman terra sigillata (Samian Ware), Vol. 7 (P to RXEAD), Institute of Classical Studies, Londres.

HAYES, J. W., 1972, Late Roman Pottery, The British School at Rome, Londres.

HUGUET, E., 2007, Terra sigil-lata tardoitàlica en la façana mediterrània de la Tarraconensis, Saguntum 39, 117-132.

ISINGS, C., 1957, Roman Glass from Dated Finds, Groninga/Yakarta.

LANCEL, S., 1967, Tipasitana I : fouilles dans la nécropole occidentale de Tipasa, Bulletin d'Archéologie Algérienne 1 (1962-1965), 39-74.

LANCEL, S., 1970, Tipasitana IV : La nécropole romaine occidentale de la Porte de Césarée : Rapport préliminaire, Bulletin d'Archéologie Algérienne 4 (1970), 149-266.

LANCEL, S., 1987, La céramique punique d'époque hellénistique, en P. LÉVÊQUE y J.-P. MOREL (eds.), Céramiques hellénistiques et romaines II, Centre de recherches d'histoire ancienne 70, 99-137.

LANDES, Ch., 1986, À propos d'un fragment de gobelet en verre sigillé orné d'un combat de gladiateurs, Pallas, Hors-série. Mélanges offerts à Monsieur Michel Labrousse, 345-362.

LE BOHEC, Y. y WOLFF, C., 2000, Legiones Moesiae Superioris, en Y. LE BOHEC (ed.), Les légions de Rome sous le Haut-Empire, Actes du Congrès de Lyon (17-19 septembre 1998), 
Collection du Centre d'Études Romaines et GalloRomaines, Nouvelle Série 2, 2 vol., París, 239-245.

LE GLAY, M., 1968, À la recherche d'Icosium, Antiquités africaines 2, 7-54.

LE GLAY, M., 1987, Alger antique (dans la voix Alger, 447-472), Encyclopédie berbère IV, AlgerAmzwar, Aix-en-Provence, 450-459.

LEVEAU, Ph., 1970, Trois tombeaux monumentaux à Cherchel, Bulletin d'Archéologie Algérienne 4, 101-148.

LEVEAU, Ph., 1976, Une area funéraire de la nécropole occidentale de Cherchel, Bulletin d'Archéologie Algérienne 5, 73-152.

LEVEAU, Ph., 1984, Caesarea de Maurétanie. Une ville romaine et ses campagnes, Collection de l'École Française de Rome 70, Roma.

MADRID, M. J. y VIZCAÍNO, J., 2006, La necrópolis tardoantigua del sector oriental de Cartagena, Anales de Arqueología Cordobesa 17, 195-224.

MESSIKH, S., 2015, Les fortifications ottomanes d'Alger (1516-1830), en P. RODRÍGUEZNAVARRO (ed.), Defensive Architecture of the Mediterranean. XV to XVIII Centuries, Proceedings of the International Conference on Modern Age Fortifications of the Western Mediterranean Coast, FORTMED 2015, Vol. 1, Valencia, 125-132.

OXÉ, A. y COMFORT, H., 2000, Corpvs Vasorvm Arretinorvm. A Catalogue of Signatures, Shapes and
Chronology of Italian Sigillata, Second edition completely revised and enlarged by Philip Kenrick, Dr. Rudolf Habelt GMBH, Bonn.

PAVOLINI, C., 1976-1977, Una produzione italica di lucerne: le Vogelkopflampen ad ansa trasversale, Bullettino della Commissione Archeologica Comunale di Roma 85, 45-134.

PETITJEAN, M., 1995, Les peignes en os à l'époque mérovingienne : évolution depuis l'Antiquité tardive, Antiquités Nationales 27, 145-191.

QUEVEDO, A., 2015, Contextos cerámicos y transformaciones urbanas en Carthago Nova (s. II-III d. C.), Roman and Late Antique Mediterranean Pottery 7, Oxford.

QUEVEDO, A., 2019, Dinámicas comerciales entre Hispania y Mauretania Caesariensis. Algunas reflexiones a partir de la evidencia cerámica (s. I-v d. C.), Zephyrus 83, 59-77.

RIPOLL, E. y MARTÍ, F., 1968, Materiales cerámicos de una cisterna romana de Ampurias, Ampurias 30, 275-292.

ROBIN PETITOT, B., 2000, Catalogue des lampes grecques et romaines, Les Collections du musée de l'Arles antique, Aviñón.

ROBIN, L., 2016, Le verre à Lyon. Production et consommation durant le Haut-Empire (Lugdunum), Monographies Instrumentum 53, Série Mobiliers lyonnais 1, Éditions Mergoil, Autun. 